\title{
Nanoindentation of single pulp fibre cell walls
}

\author{
Ramesh-Babu Adusumalli • William M. Mook • \\ Raphael Passas $\cdot$ Patrick Schwaller · Johann Michler
}

Received: 8 September 2009/Accepted: 11 January 2010/Published online: 27 January 2010

(C) Springer Science+Business Media, LLC 2010

\begin{abstract}
Unrefined chemical pulps of bleached and unbleached softwood (Scots pine, Pinus sylvestris) and hardwood (Eucalyptus, Eucalyptus globulus) were subjected to indentation tests using a nanoindenter equipped with an AFM scanner. Tests on unbleached pulps revealed no difference in hardness values between softwood and hardwood, but bleaching treatment decreased the hardness values of both pulps. Indentation modulus of $12 \mathrm{GPa}$ was observed for unbleached softwood pulps, which is $25 \%$ higher than unbleached hardwood pulps. Bleaching treatment again decreased the indentation modulus of the softwood pulps, whereas it slightly increased the indentation modulus of the hardwood pulps. After bleaching and drying processes, only negligible difference was observed in cell wall mechanical properties (hardness and indentation modulus) between hardwood and softwood pulps. This study is based on latewood pulp fibres.
\end{abstract}

\section{Introduction}

Wood cell is a complex anisotropic material and is composed of cell wall and lumen. The cell wall consists of a thin primary wall $(\mathrm{P})$, the most external layer, and

R.-B. Adusumalli $(\bowtie) \cdot$ W. M. Mook · P. Schwaller .

J. Michler

Swiss Federal Laboratories for Materials Testing and Research,

Materials Technology Department, EMPA, 3602 Thun,

Switzerland

e-mail: ramesh.adusumalli@empa.ch

\section{R. Passas}

Laboratory of Pulp and Paper Science and Graphic Arts, Grenoble INP-Pagora, 38400 Saint Martin D'Hères cedex, France secondary walls of S1 layer, S2 layer and S3 layer. The S2 wall, thickest among all cell wall layers, consists of up to $50 \%$ partly crystalline cellulose micro fibrils wound in a spiral fashion around the stem axis and embedded in a matrix of hemicellulose and lignin [15]. The spiral angle of the cellulose fibrils is known as micro fibril angle (MFA) and it is considered to be the most influential factor in wood and pulp fibre mechanical properties [1, 2, 14, 17].

Both, softwood (longer fibres, thinner cell walls in earlywood and thicker cell walls in latewood: $2-10 \mu \mathrm{m}$ ) and hardwood (shorter fibres, cell wall thickness: $2-5 \mu \mathrm{m}$ ) are used as a fibre source for paper and board [10]. Wood is converted to fibres by a pulping process. As the middle lamella is readily dissolved away by macerating solutions, chemical pulping or cooking is widely used to separate the cells (fibres) each other from the middle lamella. In chemical pulping, wood chips are chemically treated at an elevated temperature until a certain degree of delignification is attained. Unfortunately, the quantity of cellulose and hemicellulose is also degraded in chemical pulping. Bleaching is performed on pulp fibres in order to increase the brightness of the pulp. Bleaching of chemical pulps is a multi-stage process where the lignin is oxidized, decomposed and finally eliminated from the pulp fibres. As a result of cooking, bleaching and subsequent drying, pulp fibres are more collapsed (reduction in lumen size), thinwalled (P and S1 layers are peeled off) and flattened in shape compared to native wood fibres [10]. Subsequently, cell wall deformations such as wrinkles, micro-compressions, knees and twists are commonly observed in pulp fibres.

As cooking and bleaching affect the cell wall properties [15], these processes are optimized to preserve the intrinsic fibre strength and to avoid the formation of weak points in the fibre wall. Among the few studies that investigate the 
effects of cooking and bleaching, Young reported a review on certain differences within the chemical pulps (sulphite, kraft and organosolv) [28]. Page et al. [18] found that pulp fibre strength begins to decrease when the cellulose content of the fibre exceeds $80 \%$; this is where the stress distribution becomes localized due to the rigid cellulose-cellulose bonds instead of flexible cellulose-hemicellulosecellulose bonds. Fahlén and Salmén [4] and Leppänen et al. [13] reported the formation of pores in the matrix material and an enlargement of the cellulose fibril aggregates as a result of chemical pulping. In another study carried out using early wood, Peura et al. [19] reported no change in tensile properties of unbleached pulp fibres compared to native Norway spruce wood. Joutsimo [9] reported significant influence of fibre deformations (kinks and curls formed during chemical pulping) on the fibre network, but he found no influence on single fibre strength. Tchepel et al. [22] studied the effect of peroxide bleaching on thermo mechanical pulp fibres by single fibre fatigue tests. He found an increase in fibre flexibility due to a reduction in fibre cross-sectional dimension, and lower stiffnesses for bleached fibres. Additionally, classical paper testing methods such as zero-span tensile testing to understand the effect of cooking and bleaching on the fibre network have also been conducted [2, 25].

As chemical pulping involves higher pressures, high temperatures $\left(\sim 170{ }^{\circ} \mathrm{C}\right)$ and strong bleaching chemicals, it is important to perform quantitative studies of the pulp fibres at the scale of cell walls in addition to the above studies. Nanoindentation allows the measurement of the elastic modulus and the hardness at the cell wall scale [5, 24]. As the indentation displacement range is generally between 0.1 and $2 \mu \mathrm{m}$, it is possible to probe localized areas of collapsed pulp fibre cell walls having thicknesses of 2-5 $\mu \mathrm{m}$, which is difficult to achieve using normal techniques such as single fibre tensile testing. Nanoindentation of wood fibre cell walls was studied by several authors [6, 23, 26, 29]. Xing et al. [27] studied the influence of thermomecahnical refining pressure on pulp fibre properties using the nanoindentation technique. In this work, nanoindentation is performed for the first time on fibre cross sections of chemical pulp fibres in order to study the influence of fibre type and bleaching on hardness and elastic modulus.

\section{Materials and methods}

Softwood pulp (Scots pine, Pinus sylvestris) as a dry sheet of industrial quality, and hardwood pulp (Eucalyptus, Eucalyptus globulus) as pellets produced in the laboratory (Grenoble INP-Pagora, France) were used as raw materials for the present study. Kappa numbers of unbleached hardwood (HWUB), bleached hardwood (HWB), unbleached softwood (SWUB) and bleached softwood (SWB) are 13, $1.5,29$ and $<1$, respectively. Kraft fibres are selected because they are stronger and more resistant to collapse when compared to other fibres obtained through various chemical pulping techniques. As cell wall delamination is macroscopically visible in beated pulp fibres, only unbeated pulp was considered for the present study. In order to prepare the samples, a limited number of pulp fibres were suspended in water and a drop of pulp suspension was placed on a glass substrate and allowed to flow in one direction. After $24 \mathrm{~h}$ of drying, fibre bundles (partially aligned) were removed from the glass substrate and placed in a silicone mould using micro tweezers. Using alternating vacuum-pressure treatment, bundles of air-dried pulp fibres were embedded in epoxy resin and cured at $60{ }^{\circ} \mathrm{C}$ for $8 \mathrm{~h}$ [21]. The cured epoxy blocks were removed from the silicone mould and a razor blade was used to cut the epoxy blocks until fibre cross sections were exposed along the surface, which was further polished (silicon carbide abrasive papers with decreasing grit size of 2500, 1200 and 600) until a smooth surface was achieved. A microtome with a diamond rotating knife was used to further cut the surface down to the $1 \mu \mathrm{m}$ level. Specimens prepared with this method revealed smooth surfaces as shown by the light microscopy (Fig. 1) and scanning probe microscopy deflection image in the left-hand part of Fig. 2 (first derivative of the topographic image). A detailed description of the wood sample preparation for nanoindentation, which is adopted for pulp fibres, can be found in the literature [11].

After sectioning, the epoxy blocks were fixed to aluminium (Al) discs using cyanoacrylate adhesive and mounted on the magnetic sample holder of a Hysitron

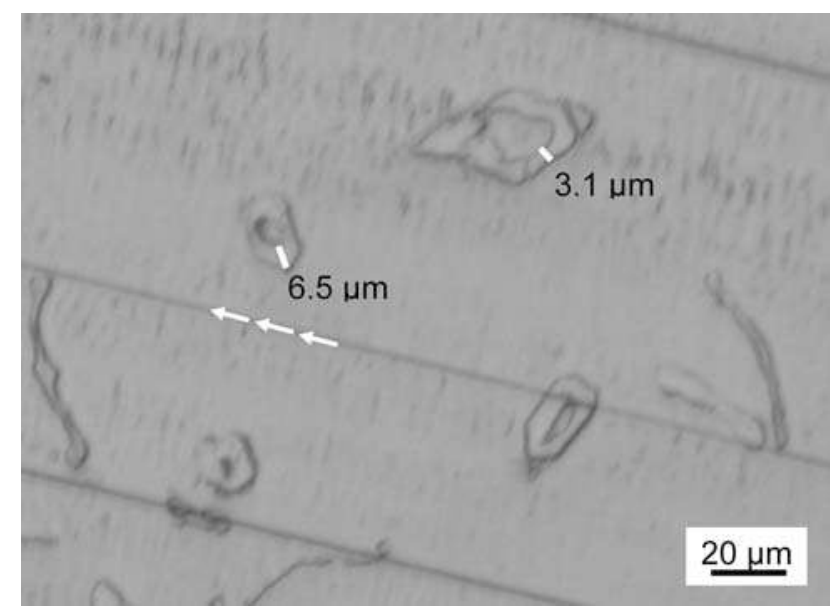

Fig. 1 Optical micrograph showing the pulp fibre cross sections and some tilted and longitudinal sections. A smooth surface was achieved by embedding the fibre bundles in epoxy resin and cutting the top surface using microtome equipped with a diamond knife. Variable cell wall thickness $(3.1-6.5 \mu \mathrm{m})$ and some processing irregularities can be seen in pulp fibre cross sections. Implanted knife markers due to sectioning are visible (white arrows) 
Fig. 2 Hysitron scanning probe microscope deflection image (first derivative of the topographic image) of bleached hardwood pulp fibre cell walls after indentation testing (left). Note the three pyramidal impressions from nanoindentation tests. Typical load-displacement graph of a nanoindentation experiment in pulp fibre cell wall and epoxy materials (right)
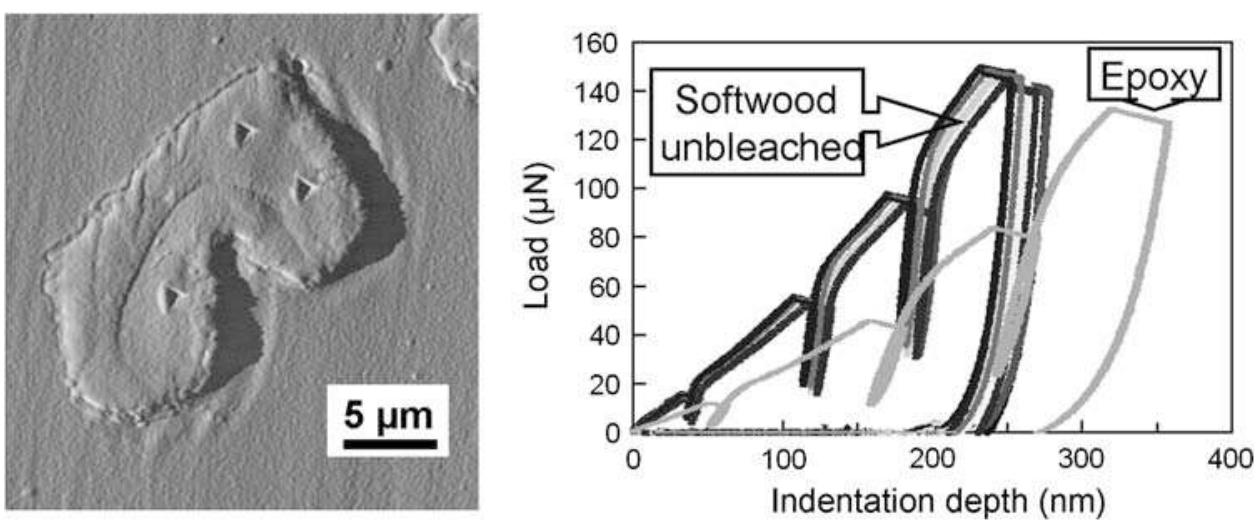

Fig. 3 Set-up for nanoindentation of single pulp fibre cell walls using Hysitron TriboIndenter
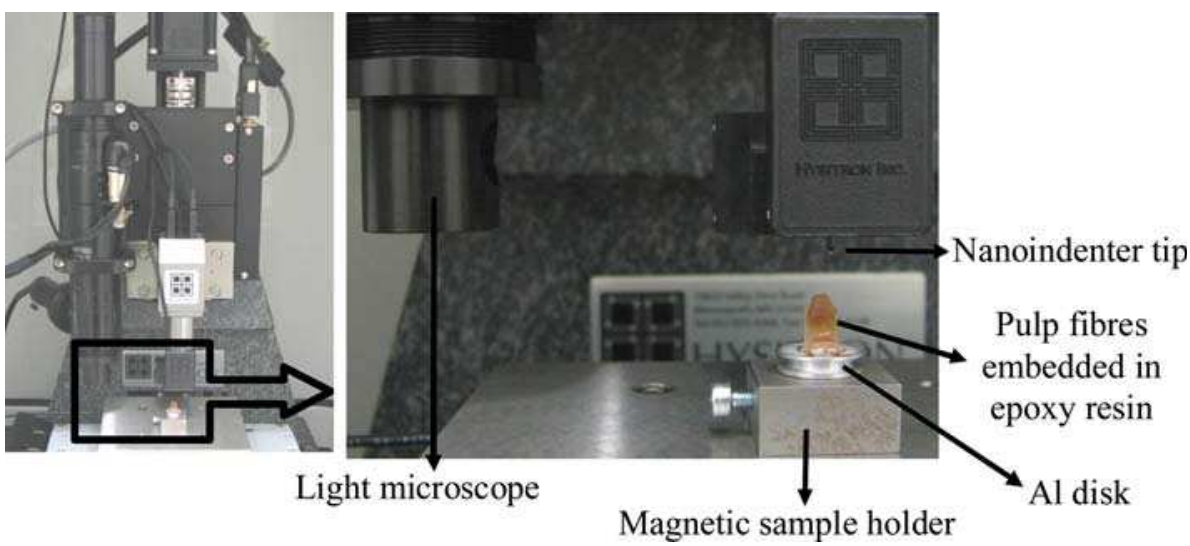

TriboIndenter (Hysitron, Inc., MN 55344, USA) as shown in Fig. 3. Indentation was performed at ambient temperature and relative humidity. Specific pulp fibres on the sample surface were located using the nanoindenter's optical microscope. Pulp containing late wood fibre cell wall cross sections was identified. In the case of hardwood pulps, only libriform fibres were considered. The indenter tip then scanned the chosen surface regions (with scan sizes up to $50 \times 50 \mu \mathrm{m}^{2}$ ) using normal forces of approximately $200 \mathrm{nN}$ such that the pulp cell wall could be found and centred underneath the tip. Indentation could be conducted with a lateral accuracy of $\pm 100 \mathrm{~nm}$ at the middle of the latewood fibre cell wall having thicknesses greater than $2.5 \mu \mathrm{m}$. Early wood fibres (cell wall thickness $\leq 2.5 \mu \mathrm{m}$ ) were not considered in this test in order to minimize the possible artefacts from cell wall borders. On average, 3-4 indents were placed on each fibre cell wall. Each indent was composed of four loading cycles with increasing peak load from $20 \mu \mathrm{N}$ in steps of $40 \mu \mathrm{N}$, resembling cyclic indentation as shown in right-hand part of Fig. 2. A maximum load of $160 \mu \mathrm{N}$ was selected to avoid the edge effects caused by low cell wall thickness, collapse behaviour of pulp fibres and to stay within the calibrated displacement range of the tip. For all steps, the loading and unloading speed was $20 \mu \mathrm{N} / \mathrm{s}$ and the holding time at peak load was $12 \mathrm{~s}$ to monitor the visco-plastic creep. An ultra sharp cube corner tip made of diamond was used to perform the indents on the fibre cross sections. Due to the micro-compressions, delaminations and kinks in the pulp fibre cell wall, a cube corner tip was selected because it is sharper and better suited for rougher samples than a Berkovich tip (http://www.hysitron.com). The load-displacement curves obtained from all experiments were evaluated according to the Oliver-Pharr method [16], where peak load $\left(P_{\max }\right)$, depth at peak load $(h)$ and initial slope of the unloading curve $(S)$ are used to measure the hardness $\left(P_{\max } / A\right)$ and reduced elastic modulus $\left(E_{\mathrm{r}}\right)$ as shown in Eq. $1 . E_{\mathrm{r}}$ is almost identical to $E$ in case of soft materials like pulp and it is termed as indentation modulus throughout this article. The contact area $A$ at $P_{\max }$ is determined from the known shape of the indenter, which is calibrated by indenting a material with known properties (in this case fused quartz).

$E_{\mathrm{r}}=\frac{1}{2} \sqrt{\pi} \frac{S}{\sqrt{A}}$.

\section{Results and discussion}

Figure 1 shows an optical micrograph of pulp fibres embedded in epoxy resin and sectioned until a smooth surface is achieved as explained in the previous section. 
This micrograph is taken prior to nanoindentation using normal reflected light microscopy in order to map the latewood cell cross sections. Undoubtedly, this micrograph reveals not only fibre cross sections but also some tilted (misaligned fibre cross sections) and longitudinal sections due to the fibre misalignment. As pulp fibres are 1-3 mm length and highly flexible, it is difficult to achieve a specimen with all fibres aligned in one direction. As the indentation modulus depends on the fibre misalignment [12], care is taken to select only longitudinally aligned fibre cross sections, which are free from other artefacts such as knife markers. One way of checking the fibre alignment is to compare the shapes of the fibre cross section before indentation and after indentation followed by $5 \mu \mathrm{m}$ sectioning.

The scanning probe microscopy image of residual indents on pulp fibre cell wall after nanoindentation is shown in left-hand part of Fig. 2. This fibre is fully collapsed (negligible lumen) and compressed such that the lumen exhibits variability in its cell wall thickness. However, no variability in indentation modulus $E_{\mathrm{r}}$ and hardness $H$ was observed across the cell wall. This is most likely because indents were performed on very localized areas of the cell wall where minimal cell wall defects were found. So it is assumed that $E_{\mathrm{r}}$ and $H$ values obtained from nanoindentation tests are higher than average values. Typical load-depth curves of pulp fibre and epoxy are displayed in the right-hand part of Fig. 2. Both pulp and epoxy revealed elasto-plastic behaviour during loading and unloading and some creep while holding at the peak load was also observed. However, for a given load, the slope of the unloading curve is higher and maximum indentation depth is lower for pulp fibre when compared to epoxy.

Indentation modulus $E_{\mathrm{r}}$ and hardness $H$ values of different pulp grades are displayed in Figs. 4 and 5, respectively. On average, more than 30 measurements were used for each fibre type. In many tests, a slight decrease in $E_{\mathrm{r}}$ and $H$ was observed with increasing indentation depth. Similarly nanoindentation of viscose and lyocell fibres also revealed a decrease in hardness and elastic modulus with increasing indentation depth [7]. We assume this is not due to the surrounding epoxy but due to the difficulties in detecting the surface contact at low loads [8]. The quantitative analysis of nanoindentation data revealed an average $E_{\mathrm{r}}$ and $H$ of $12.2 \pm 1.6$ and $0.42 \pm 0.05 \mathrm{GPa}$, respectively, for $\mathrm{S} 2$ cell walls of unbleached scots pine pulp. For S2 wall of spruce latewood, Zickler et al. [29] reported average $E_{\mathrm{r}}$ and $H$ of 14.2 and $0.40 \mathrm{GPa}$, respectively. Gindl et al. [6] reported $E_{\mathrm{r}}$ of 16.2 and $H$ of $0.43 \mathrm{GPa}$ for the latewood Norway spruce (MFA $20^{\circ}$ ). So, the values of the unbleached softwood pulp are in good agreement with the values presented by Zickler and Gindl.

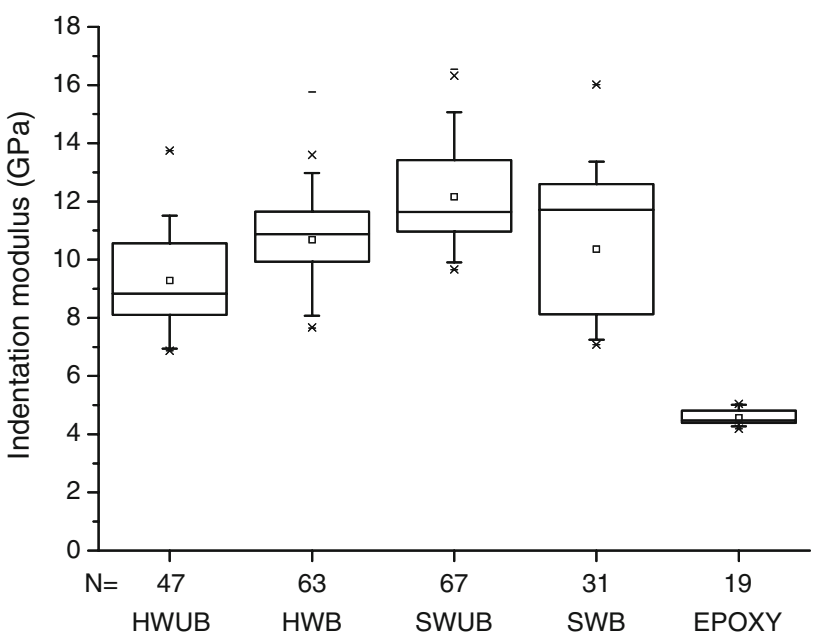

Fig. 4 Nanoindentation results showing indentation modulus or reduced elastic modulus of pulp fibre cell walls and epoxy resin ( $H W U B$ hardwood unbleached, $H W B$ hardwood bleached, SWUB softwood unbleached, $S W B$ softwood bleached, $N$ number of samples). The box and whisker plot shows the mean value (small square in the box), median (horizontal line inside the box), the $50 \%$ interquartile range (box), maximum and minimum values (whiskers) and outliers

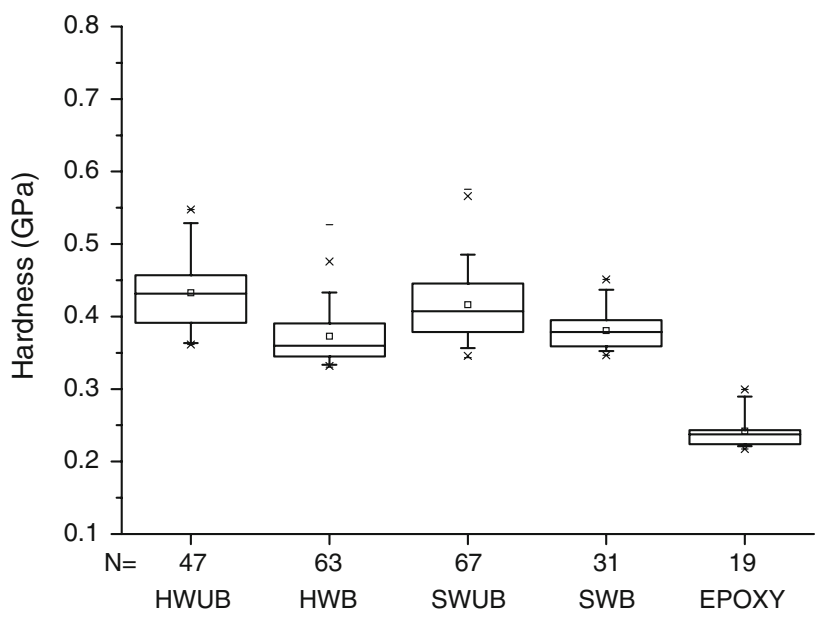

Fig. 5 Nanoindentation results showing the hardness of pulp fibre cell walls and epoxy ( $H W U B$ hardwood unbleached, $H W B$ hardwood bleached, $S W U B$ softwood unbleached, $S W B$ softwood bleached, $N$ number of samples)

$E_{\mathrm{r}}$ of $9.1 \pm 1.6$ and $H$ of $0.43 \pm 0.05 \mathrm{GPa}$ was obtained for unbleached eucalyptus pulp. Wu et al. reported an $E_{\mathrm{r}}$ of 20.2 and $H$ of $0.49 \mathrm{GPa}$ as an average values of 10 hardwood species [26]. In Figs. 4 and 5, $E_{\mathrm{r}}$ and $H$ of epoxy resin (embedding medium) were determined to be 4.6 and $0.24 \mathrm{GPa}$, respectively, which were measured simultaneously with pulp cell wall measurements. Gindl and Gupta [5] presented the $E_{\mathrm{r}}$ and $H$ of same epoxy resin as 3.1 and $0.10 \mathrm{GPa}$, respectively, where a berkovich tip was loaded to a peak force of $500 \mu \mathrm{N}$. 
Regarding $E_{\mathrm{r}}$ shown in Fig. 4, unbleached hardwood showed significantly lower values than unbleached softwood. After the bleaching treatment, both hardwood and softwood revealed a similar Er value of $\sim 11 \mathrm{GPa}$ for a similar Kappa number of $\sim 1$ (lignin content $0.2 \%$ ). For a similar indentation depth, Gindl et al. [7] reported an $E_{\mathrm{r}}$ of $\sim 11 \mathrm{GPa}$ for lyocell fibre composed of $100 \%$ cellulose fibre. As $E_{\mathrm{r}}$ is directly proportional to MFA as revealed by several nanoindentation measurements $[6,26]$, it is difficult to interpret the $E_{\mathrm{r}}$ values of different pulp grades shown in Fig. 4 without the MFA measurements. However, it is difficult to evaluate the accurate MFA of pulp fibres especially where indentation is performed, although some studies have been reported in literature [3, 20].

Hardness values measured from nanoindentation are shown in Fig. 5. As $H$ is a plastic property of the material unlike $E_{\mathrm{r}}$, MFA does not influence the hardness value, which could be the reason that no difference in $H$ was observed between softwood and hardwood in the present study. This supports the recent study that nanoindentation hardness is related to the cell wall matrix [12]. Similarly, $\mathrm{Wu}$ et al. [26] also found no significant trend between nanoindentation hardness and MFA of 10 hardwood species. In general, bleaching treatment increases the ductility of the cell wall assembly by degrading the lignin, which eventually leads to lower hardness values compared to the unbleached fibres of both hardwood and softwood as shown in Fig. 5. This can be understood as follows: the lignin content of the wood is around $23 \%$, and cell wall hardness is around $0.42 \mathrm{GPa}$ (unpublished data). Based on the Kappa numbers measured in this study, the lignin content of the unbleached softwood and hardwood pulp is around 4.4 and 2\%, respectively. Even though lignin content decreased significantly from wood to unbleached pulps, the hardness value remained constant, i.e. $\sim 0.42 \mathrm{GPa}$. The lignin content of the bleached fibres is measured to be $0.2 \%$, and their hardness values are in the range of $0.36 \mathrm{GPa}$. That means removal of the lignin-hemicellulose matrix during bleaching plays a significant role in stress transfer between cellulose microfibrils. When the lignin content is further reduced e.g. zero percentage in lyocell fibres, the hardness value drops drastically to $0.24 \mathrm{GPa}$, in which only hydrogen bonding and van der Waals bonding takes place between cellulose-cellulose molecules.

\section{Conclusion}

We have shown that nanoindentation can be used as a tool to estimate changes in the cell walls caused by bleaching and also to study the differences in cell wall mechanical properties between hardwood and softwood.
- Within a pulp cell wall, no change in indentation modulus and hardness was observed.

- After kraft cooking, prior to bleaching, indentation modulus of $12 \mathrm{GPa}$ was observed for softwood pulp, which is $25 \%$ higher than hardwood pulp and $30 \%$ lower than softwood. With respect to hardness, no difference was observed between wood and pulp.

- However, bleaching treatment decreased the hardness value of both softwood and hardwood pulps indicating the importance of critical kappa number (lignin content) during residual delignification.

- After cooking, bleaching and drying stages, both hardwood and softwood fibres have similar $E_{\mathrm{r}}$ $(\sim 10.5 \pm 2.1 \mathrm{GPa})$ and $H(\sim 0.377 \pm 0.033)$.

Acknowledgements This research was funded by State Secretariat for Education and Research, Switzerland (Grant number: C.07.0023) and partly funded by the COST-European Cooperation in Science and Technology (Action number: E54). We are very thankful to Prof. Ralph Spolenak and Dr. Marianne Dietiker from the Department of Materials, ETH Zürich, Switzerland for allowing us to use their Hysitron TriboIndenter. Dr. Jean-Marc Breguet (CSEM, Switzerland) is gratefully acknowledged for his contribution to the project proposal. The authors would like to thank Dr. Kilian Wasmer and Mr. Peter Ramseier for their contribution in specimen preparation. Dr. Tanja Zimmermann is greatly acknowledged for her helpful comments on the manuscript.

\section{References}

1. Barnett JR, Bonham VA (2004) Biol Rev 79:461

2. Courchene CE, Peter GF, Litvay J (2006) Wood Fibre Sci 38(1): 112

3. Donaldson LA (1991) Wood Fibre Sci 23(2):290

4. Fahlén J, Salmén L (2005) Biomacromolecules 6:433

5. Gindl W, Gupta HS (2002) Composites A 33:1141

6. Gindl W, Gupta HS, Schöberl T, Lichtenegger HC, Fratzl P (2004) Appl Phys A 79:2069

7. Gindl W, Konnerth J, Schöberl T (2006) Cellulose 13:1

8. Jakes JE, Stone DS, Frihart CR (2007) Proceedings of 30th annual meeting of the adhesion society, Inc, Tampa Bay, Florida, USA, p 15

9. Joutsimo O (2004) PhD thesis, Helsinki University of Technology, Finland

10. Karlsson H (2006) Fibre guide-fibre analysis and process applications in the pulp and paper industry. AB Lorentzen \& Wettre, Sweden. ISBN: 91-631-7899-0

11. Konnerth J, Harper D, Lee SH, Rials TG, Gindl W (2008) Holzforschung 62:91

12. Konnerth J, Gierlinger N, Keckes J, Gindl W (2009) J Mater Sci 44:4399. doi:10.1007/s10853-009-3665-7

13. Leppänen K, Andersson S, Torkkeli M, Knaapila M, Kotelnikova N, Serimaa R (2009) Cellulose 16(6):999

14. Lichtenegger H, Reiterer A, Stanzl-Tschegg SE, Fratzl P (1999) J Struct Biol 128:257-269

15. Paavilainen L (2002) In: Mark RE, Habeger CC Jr, Borch J, Lyne MB (eds) Handbook of physical testing of paper, vol 1, chap 13. Marcel Dekker, Inc., New York, p 699. ISBN: 0-8247-0498-3

16. Oliver WC, Pharr GM (1992) J Mater Res 7:1564 
17. Page DH, Hosseiny FEl (1983) J Pulp Paper Sci (September edition):99

18. Page DH, Seth RS, Hosseiny FEI (1985) Transactions of the eighth fundamental research symposium. MEP, Oxford, London, p 77

19. Peura M, Grotkopp I, Lemke H, Vikkula A, Laine J, Müller M, Serimaa R (2006) Biomacromolecules 7:1521

20. Pleasants S, Batchelor WJ, Parker IH (1998) APPITA 51(5):373

21. Spurr AR (1969) J Ultra Struct Res 26:31

22. Tchepel MV, Mcdonald JD, Dixon T (2006) J Pulp Paper Sci 32(2): 100

23. Tze WTY, Wang S, Rials TG, Pharr GM, Kelley SS (2007) Composites A 38:945
24. Wimmer R, Lucas BN, Tsui TY, Oliver WC (1997) Wood Sci Technol 31:131

25. Wimmer R, Downes G, Evans R, French J (2008) Ann For Sci 65(6):602

26. Wu Y, Wang S, Zhou D, Xing C, Zhang Y (2009) Wood Fibre Sci 41(1):64

27. Xing C, Wang S, Pharr GM, Groom LH (2008) Holzforschung 62:230

28. Young RA (1994) Cellulose 1:107

29. Zickler GA, Schöberl T, Paris O (2006) Philos Mag 86(10):1373 